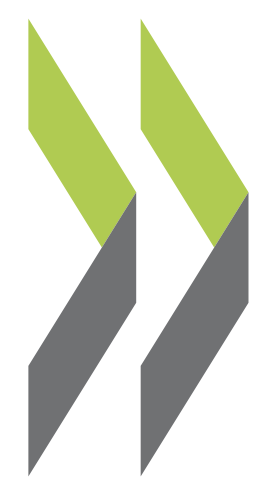

OECD Regional Development Working Papers 2011/06

OECD Extended Regional Typology: The Economic Performance of Remote Rural Regions

Monica Brezzi, Lewis Dijkstra, Vicente Ruiz 


\section{OECD REGIONAL DEVELOPMENT WORKING PAPERS}

This series is designed to make available to a wider readership selected studies on regional development issues prepared for use within the OECD. Authorship is usually collective, but principal authors are named.

The papers are generally available only in their original language English or French with a summary in the other if available.

The opinions expressed in these papers are the sole responsibility of the author(s) and do not necessarily reflect those of the OECD or the governments of its member countries.

Comment on the series is welcome, and should be sent to either gov.contact@oecd.org or the Public Governance and Territorial Development Directorate, 2, rue André Pascal, 75775 PARIS CEDEX 16, France.

OECD Regional Development Working Papers are published on www.oecd.org/gov/regional/workingpapers

Applications for permission to reproduce or translate all or part of this material should be made to: OECD Publishing, rights@oecd.org or by fax 33145249930.

(C) OECD 2011 


\begin{abstract}
To account for differences among rural and urban regions, the OECD s established a regional typology, classifying TL3 regions as predominantly urban (PU), intermediate (IN) or predominantly rural (PR) (OECD, 2009). This typology, based essentially on the percentage of regional population living in urban or rural communities, has proved to be meaningful to better explain regional differences in economic and labour market performance. However this typology does not take into account the presence of economic agglomerations if they happen to be in neighbouring regions. For example, a region is classified as rural or intermediate regardless its distance from a large urban centre where labour market, access to services, education opportunities and logistics for firms can be wider.

Previous work reveals great heterogeneity in economic growth among rural regions and the distance from a populated centre could be a significant factor explaining these differences. For the latter, the OECD regional typology is extended to include an accessibility criterion. This criterion is based on the driving time needed for at least half of the population in a region to reach a populated centre of with 50000 or more inhabitants. The resulting classification consists of four types of regions: Predominantly Urban (PU), Intermediate (IN), Predominantly Rural Close to a city (PRC) and Predominantly Rural Remote (PRR). For the time being, the extended typology has only been computed for regions in North America (Canada, Mexico and the United States) and Europe.

The extended typology is used to compare the dynamics of population and labour markets. Remote rural regions show a stronger decline in population and a faster ageing process than rural regions close to a city. The remoteness of rural regions is in fact a significant factor explaining regional outflows of working age population, confirming that this extended typology captures the economic distance from market and services. Remote rural regions appear economically more fragile: lower employment rates (Canada and Mexico) and economic output (Europe).

Afin de prendre en compte les différences entre les régions rurales et urbaines, l'OCDE a établi une typologie régionale qui classe les régions TL3 en 3 catégories : régions majoritairement urbaines (PU), intermédiaires (IN) ou à prédominance rurale (PR), (OCDE, 2009). Cette typologie, qui repose essentiellement sur le pourcentage de la population régionale vivant dans des communautés urbaines ou rurales, s'est révélée significative pour mieux expliquer les différences régionales au niveau de la performance économique et du marché du travail. Toutefois, cette typologie ne tient pas compte de la présence de grandes agglomérations, si celles-ci se trouvent dans des régions voisines. Par exemple, une région est considérée comme rurale ou intermédiaire indépendamment de sa distance d'un grand centre urbain, où le marché du travail, l'accès aux services, les possibilités d'éducation et l'offre logistique pour les entreprises peuvent être meilleurs.
\end{abstract}

Des travaux antérieurs révèlent une grande hétérogénéité de croissance économique entre les régions rurales, et la distance d'un centre fortement peuplé pourrait être un facteur important pour expliquer ces différences. C'est pour cette raison que la typologie régionale de l'OCDE a été élargie afin d'y inclure un critère d'accessibilité. Ce critère est basé sur le temps de trajet que doit réaliser au moins la moitié de la population d'une région pour atteindre un centre urbain de 50000 habitants ou plus. La classification qui en résulte se compose de quatre types de régions: Majoritairement Urbaines (PU), Intermédiaires (IN), à prédominance rurale proches d'une ville (RPC) et à prédominance rurale éloignées (PRR). Pour l'heure, la typologie élargie n'a été calculée que pour les régions en Amérique du Nord (Canada, Mexique, États-Unis) et en Europe.

La typologie élargie est utilisée pour comparer la dynamique de la population et celle des marchés du travail. Elle montre que les régions rurales éloignées ont une baisse plus importante de leur population et un processus de vieillissement plus rapide que les régions rurales proches d'une ville. L'éloignement des régions rurales est en effet un facteur important pour expliquer les migrations régionales de la population en âge de travailler, ce qui confirme que cette typologie élargie prend bien en compte la distance économique du marché et des services. Les régions rurales éloignées apparaissent plus fragiles au niveau économique : des taux d'emploi inférieurs (Canada et Mexique) et une production économique moindre (Europe).

JEL Classification: R1, R4, J61, C80

Key words: rural regions, distance to markets, OECD regional typology, labour market mobility, ageing, road networks. 


\section{FOREWORD}

This working paper is one in a series of OECD Regional Development Working Papers of the OECD Public Governance and Territorial Development Directorate.

This paper has been produced by Monica Brezzi and Vicente Ruiz of the OECD Secretariat, and Lewis Dijkstra of Directorate for Regional Policy at the European Commission under the supervision of Joaquim Oliveira Martins (Head of the Regional Development Policy Division, OECD). The authors thank the Delegates of the OECD Working Party on Territorial Indicators for valuable comments on earlier versions and help with the data. Special thanks are given to Hugo Poelman (EC-Dg Regio) for providing the analysis on European regions.

The paper can be downloaded on the OECD website: www.oecd.org/gov/regional/statisticsindicators.

Further enquiries about this paper and OECD work on regional statistics and analysis should be addressed to Monica Brezzi (monica.brezzi@oecd.org). 


\section{Introduction}

Regional differences in economic and social outcomes within OECD countries tend to be greater than the differences among countries. This regional heterogeneity imposes significant challenges, among others, regarding the allocation of resources to both local authorities and national governments.

There are many country-specific factors contributing to these regional differences. The concentration of population in a region, as to spur economic agglomerations and economies of scale, is a plausible indicator to explain part of the regional heterogeneity. Taken this into account, the OECD established a regional classification or typology based on the percentage of regional population living in urban and rural communities.

The OECD typology has proved to be meaningful in better explaining regional differences in economic and labour market performance (OECD 2011). Nevertheless, being based on the local concentration of the population, it cannot discriminate between those regions that are close to a large populated centre and those that are remote. Since remote regions (in particular rural regions) may face a different set of problems, compare to regions surrounding a big populated centre, their performance remains as one of the most relevant topics in the regional policy agenda.

Refinements of the OECD regional typology to take into account additional criteria beside the density of population have been discussed among Delegates of the OECD Working Party on Territorial Indicators. An extension to the current typology is here applied to North America and Europe, by introducing a measure of distance to urban centre, following the examples of some countries (Bollman 2008) as well as an application to European countries carried out by the European Commission (Dijkstra and Poelman 2008). This extended typology was adopted by the OECD Working Party on Territorial Indicators in 2009.

The purpose of this paper is twofold:

a) It describes the methodology to extend the current typology in order to account for the accessibility to populated centres. This extension to the current typology provides the means to discriminate between rural regions close to a populated centre and remote regions. The necessary steps to apply the same methodology to the other OECD countries are also described.

b) It analyses the performance of remote rural regions in both Europe and North America (Canada, Mexico and the United States) by looking at population dynamics, employment and GDP trends.

The first paragraph describes the motivation behind the adoption of this new methodology and provides a brief description of its main components. The second paragraph shows the results of applying the extended typology to North American and European regions. The third paragraph highlights the performance of remote rural regions in Europe and North America on population dynamics, labour mobility and economic performance. Finally, the annex of the document includes a detailed description of the methodology used to extend the OECD typology and a list of the data needed in order to extend this methodology to other countries.

\section{Extending the OECD regional typology}

Despite that the causality between economic growth and transport infrastructure is not always clear, the access to goods and services is generally considered an important component for improving regional wellbeing. From a public point of view, a better access to populated centres could provide to the population of neighbouring regions with the benefits generated by agglomeration economies. In practice, these benefits are translated not only in terms of a bigger choice of goods and services, but also in terms of accessing to a larger labour market, more specialised medical services and better education opportunities.. 
The use of concentration measures, generally based on local population, has been a consistent and practical way to account for some of the regional heterogeneity. Following this line of thought, the OECD created a regional typology based on the percentage of regional population living in local rural areas and on the existence of important urban centres where at least $25 \%$ of the regional population resides, (OECD 2009). Based on the latter, the TL3 regions of OECD member countries are classified as predominantly urban (PU), intermediate (IN) and predominantly rural (PR).

The OECD typology has proved to be meaningful in better explaining regional differences in economic and labour market performance (OECD 2011). Nevertheless, being based on the local concentration of the population, it cannot take into account the presence of economic agglomerations if they happen to be in neighbouring regions. Indeed, regions are classified as rural or intermediate regardless to their distance to large populated centres. Moreover, the OECD typology is unable to discriminate between those intermediate and rural regions that are close to a large populated centre and those that are remote.

In order to account for the regional difference, due to the access to populated centres, the OECD regional typology has been extended. This extension provides an additional criterion based on the driving time needed for $50 \%$ of the population of a region to reach a populated centre (Dijkstra and Poelman, 2008). This additional criterion does not affect the classes or types of regions provided by the OECD regional typology. The extended typology only further classifies intermediate and rural regions into remote or close to a populated centre. The resulting classification consists of five types of regions: Predominantly Urban (PU), Intermediate Close to a city (INC), Intermediate Remote (INR), Predominantly Rural Close to a city (PRC) and Predominantly Rural Remote (PRR).

For the time being the extended typology has only been applied to North American and European regions, where different sets of parameters have been used to establish the classification. The results of the extended typology depend on the parameters used for defining both the time needed to reach a populated centre and the size of the populated centre itself. After consulting with a panel of experts, it was agreed that populated centres with a population of at least 50000 inhabitants could be considered "big" enough to provide the set of benefits derived from agglomeration economies that intermediate and rural regions could profit from. Regarding the time needed to reach a populated centre, after considering different time frames and testing the sensitivity of the results, the time thresholds of 45 and 60 minutes were chosen for Europe and North America respectively.

The extended typology classifies then rural and intermediate regions as remote when $50 \%$ of the regional population needs at least 60 (45) minutes of driving time to reach a populated centre with at least 50000 inhabitants. If this condition does not hold, then rural and intermediate regions are classified as close to a populated centre.

\section{Results of the extended typology in North America and Europe}

According to the OECD regional typology 74\% of the TL3 regions in North America are rural. Once the extended typology is applied, more than half of the rural regions become remote rural regions (260 regions). In Canada, $74 \%$ of rural regions are reclassified as remote, while in the United States only $25 \%$. In terms of population, of the around 150 million inhabitants of rural regions in North America, 17\% resides in remote rural regions. However, this percentage varies among the three countries, $57 \%$ of the population resides in remote rural regions in Canada, $27 \%$ in Mexico and only $11 \%$ in the US. Compared to North America the percentage of rural regions in Europe is significantly smaller. Indeed, following the OECD typology, only 35\% of the European regions are classified as PR and 14\% of European regions are classified as remote rural regions (PRR) corresponding to the $5 \%$ of population (Table 1). 
Table 1. Percentage of the population by extended typology

\begin{tabular}{lllllll}
\hline Country & PU & INC & INR & PRC & PRR & Total \\
\hline AUSTRIA & $23 \%$ & $31 \%$ & $0 \%$ & $35 \%$ & $11 \%$ & $100 \%$ \\
BELGIUM & $83 \%$ & $14 \%$ & $0 \%$ & $2 \%$ & $0 \%$ & $100 \%$ \\
CANADA & $48 \%$ & $19 \%$ & $0 \%$ & $20 \%$ & $13 \%$ & $100 \%$ \\
CZECH REPUBLIC & $11 \%$ & $84 \%$ & $0 \%$ & $5 \%$ & $0 \%$ & $100 \%$ \\
DENMARK & $29 \%$ & $28 \%$ & $0 \%$ & $24 \%$ & $19 \%$ & $100 \%$ \\
FINLAND & $26 \%$ & $9 \%$ & $4 \%$ & $42 \%$ & $20 \%$ & $100 \%$ \\
FRANCE & $35 \%$ & $48 \%$ & $0 \%$ & $13 \%$ & $4 \%$ & $100 \%$ \\
GERMANY & $56 \%$ & $26 \%$ & $0 \%$ & $18 \%$ & $0 \%$ & $100 \%$ \\
GREECE & $36 \%$ & $24 \%$ & $0 \%$ & $5 \%$ & $35 \%$ & $100 \%$ \\
HUNGARY & $17 \%$ & $42 \%$ & $0 \%$ & $22 \%$ & $19 \%$ & $100 \%$ \\
ICELAND &. &. &. &. &. &. \\
IRELAND & $28 \%$ & $0 \%$ & $0 \%$ & $45 \%$ & $27 \%$ & $100 \%$ \\
ITALY & $52 \%$ & $36 \%$ & $3 \%$ & $6 \%$ & $3 \%$ & $100 \%$ \\
MEXICO & $47 \%$ & $17 \%$ & $0 \%$ & $26 \%$ & $9 \%$ & $100 \%$ \\
NETHERLANDS & $85 \%$ & $15 \%$ & $0 \%$ & $0 \%$ & $0 \%$ & $100 \%$ \\
NORWAY & $12 \%$ & $35 \%$ & $5 \%$ & $4 \%$ & $45 \%$ & $100 \%$ \\
POLAND & $23 \%$ & $29 \%$ & $2 \%$ & $45 \%$ & $1 \%$ & $100 \%$ \\
PORTUGAL & $52 \%$ & $24 \%$ & $2 \%$ & $6 \%$ & $15 \%$ & $100 \%$ \\
SLOVAK REPUBLIC & $11 \%$ & $63 \%$ & $0 \%$ & $25 \%$ & $0 \%$ & $100 \%$ \\
SPAIN & $48 \%$ & $36 \%$ & $2 \%$ & $8 \%$ & $6 \%$ & $100 \%$ \\
SWEDEN & $21 \%$ & $30 \%$ & $0 \%$ & $29 \%$ & $20 \%$ & $100 \%$ \\
SWITZERLAND & $41 \%$ & $45 \%$ & $4 \%$ & $3 \%$ & $6 \%$ & $100 \%$ \\
TURKEY & $47 \%$ & $25 \%$ & $0 \%$ & $22 \%$ & $5 \%$ & $100 \%$ \\
UNITED KINGDOM & $70 \%$ & $27 \%$ & $1 \%$ & $2 \%$ & $0 \%$ & $100 \%$ \\
UNITED STATES & $43 \%$ & $20 \%$ & $0 \%$ & $33 \%$ & $4 \%$ & $100 \%$ \\
\hline
\end{tabular}

The extended typology has a negligible effect on the number of intermediate regions in Europe and Mexico and none effect in the United States. In Canada around 20\% of the intermediate regions become remote intermediate. Also in terms of the population the effect is quite limited, the largest being in Canada where $7 \%$ of the population in intermediate regions resides in remote intermediate regions, while in Mexico the percentage of people living in this type of regions is $2 \%$ and $1 \%$ in Europe (Table 1).

The regions in North America and Europe by the extended typology are shown in Figure 1. Considering the limited number of remote intermediate regions, the rest of the analysis will focus only on four categories: PU, INC, PRR and PRC. 
Figure 1. Extended Typology North-America

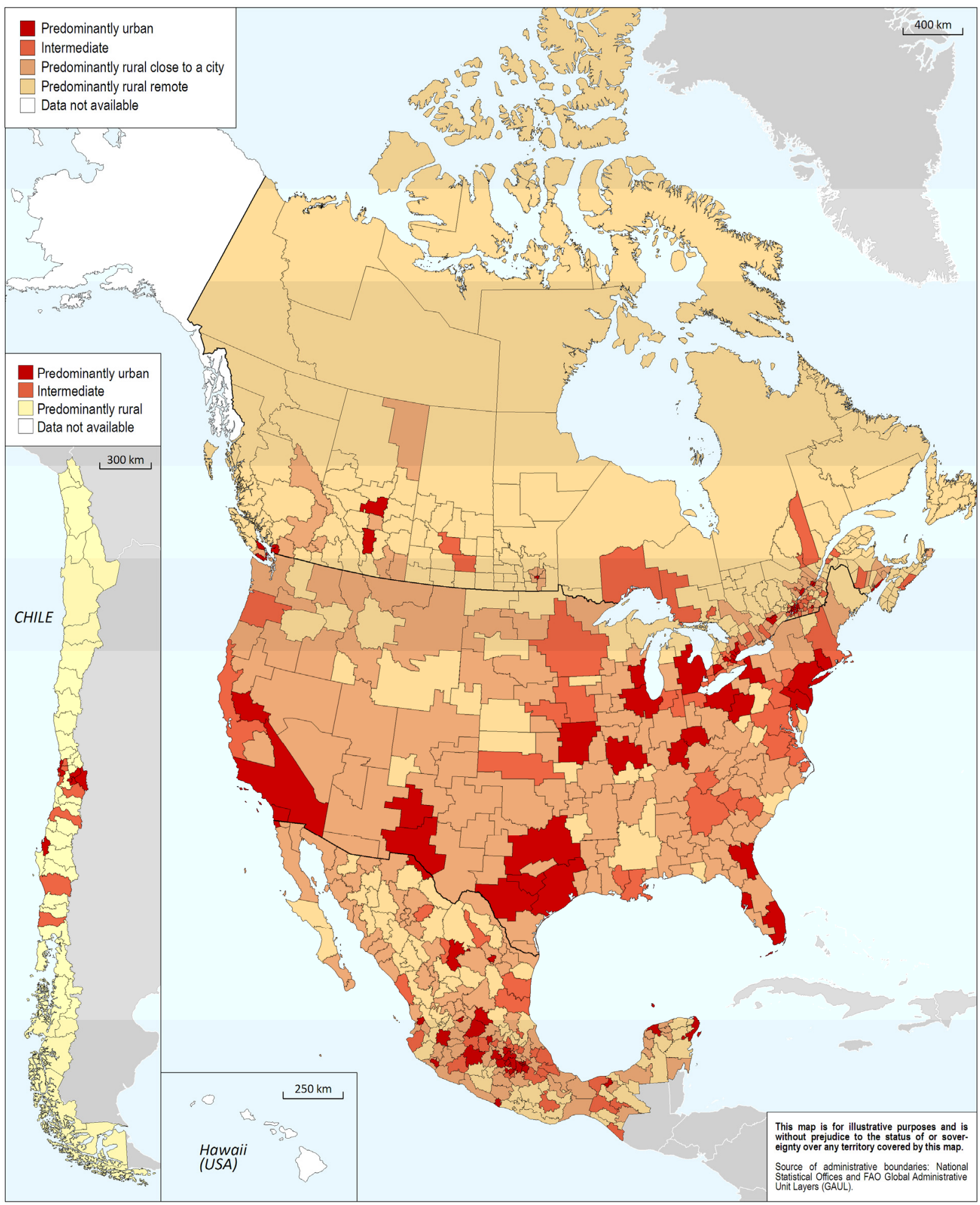


Figure 2. Extended Typology Europe

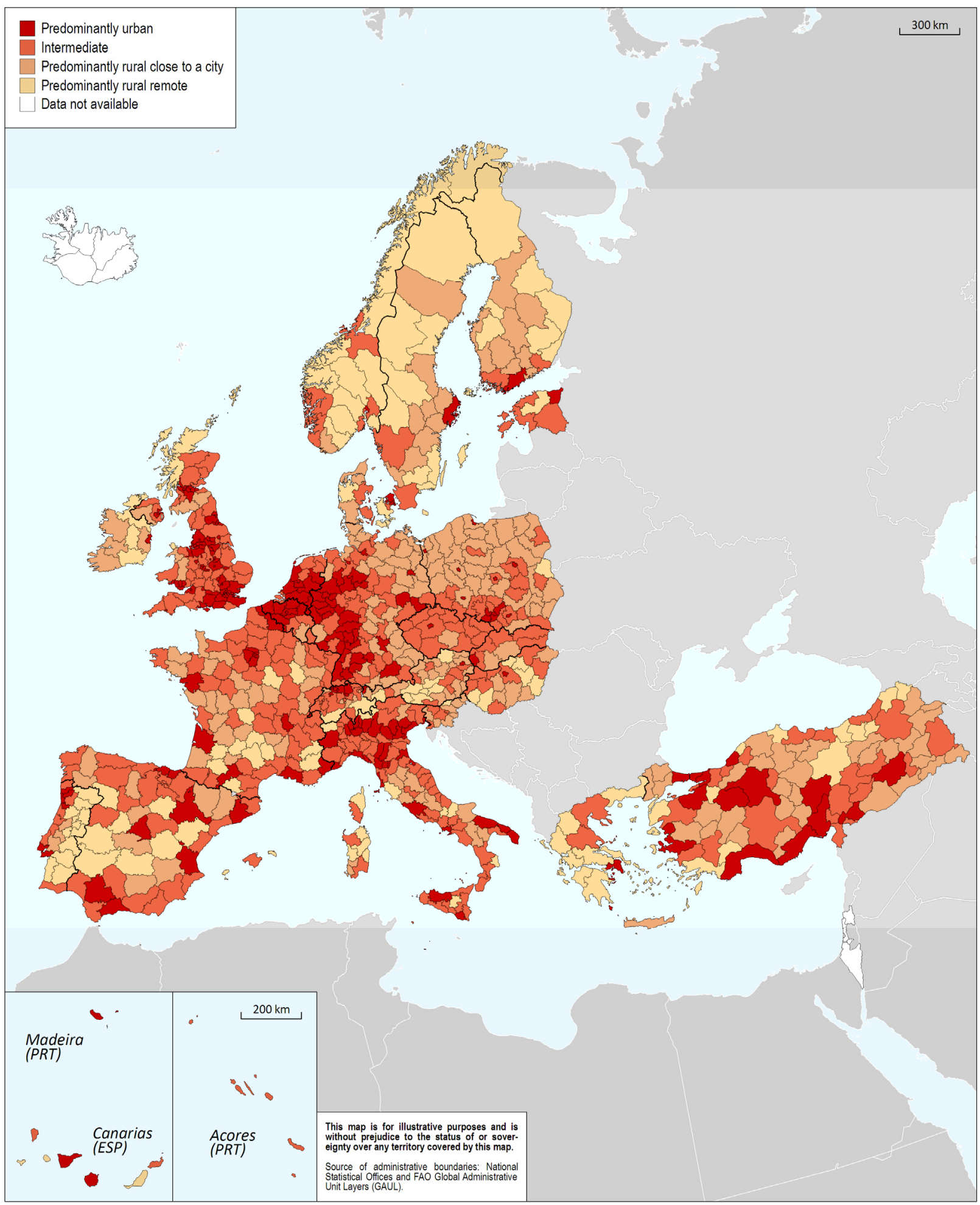




\section{Regional performance based on the extended regional typology}

Remote rural regions tend to experience slower population growth. In Canada and Mexico, this group of regions is the one affected by negative population growth on average (Figure 3 ).

Figure 3. Annual population growth rate in North American and European regions by extended regional typology
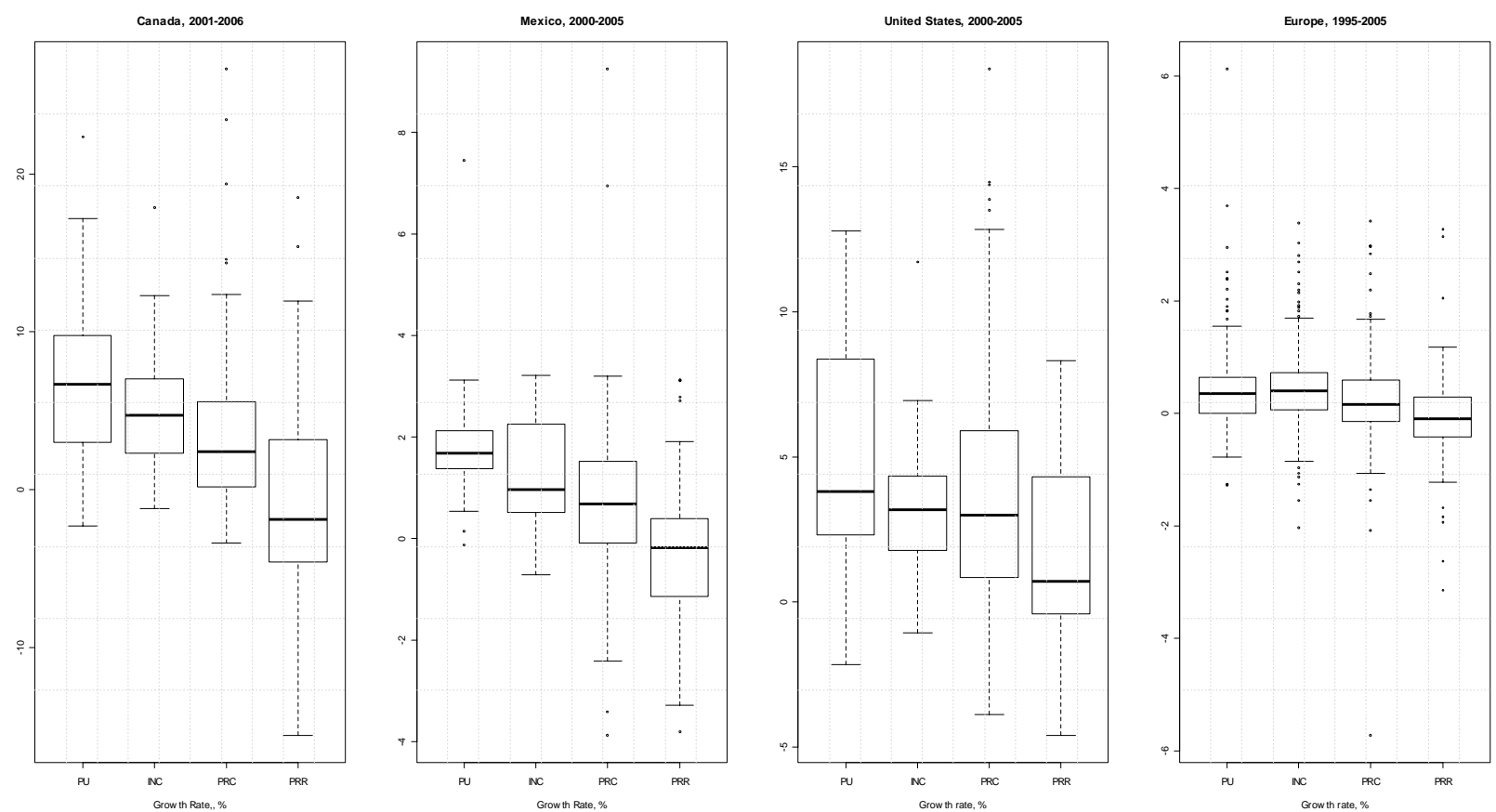

The effects of remoteness can also be seen on the dynamics of the population in the United States. Population growth rates tend to significantly differ between PRR and PRC (Figure 3). On average, the population growth rate of regions close to a city is two times higher than the one of remote regions (3.7\% compare to $1.4 \%$ ). Moreover, the PRR class includes the region with lowest growth rate in the US, Salina (Kansas) (-4.6\%), while the PRC class includes the region with the highest rate, Las Vegas (Nevada) (18.36\%). The dynamics of the population of European regions, based on the extended typology, seem to be similar to the ones from North American regions: on average, PRR tend to have the smaller growing rates. However, in the case of Europe, we can appreciate that the distributions of the population growing rates tend to be more similar among each others. All these distributions are also characterised by a significant amount of outliers, which calls for further investigation.

Interregional mobility within countries and migration are important components of the change in the demographic structure, indicating whether the ageing of certain areas is reinforced by outflows of the working age population. A recent analysis carried out on 22 OECD countries show not only that, as expected, remote rural regions display net outflows more often than the other types of regions (Figure 4), but also that the remoteness of a region is a significant factor to predict the loss of population, while the rurality when combined with the production structure of a region (OECD 2010). In other words, economic diversification and links with large urban centres are critical to the ability of rural regions to retain population. 
Figure 4. Percentage of TL3 remote rural regions with negative flows, last 3 available years

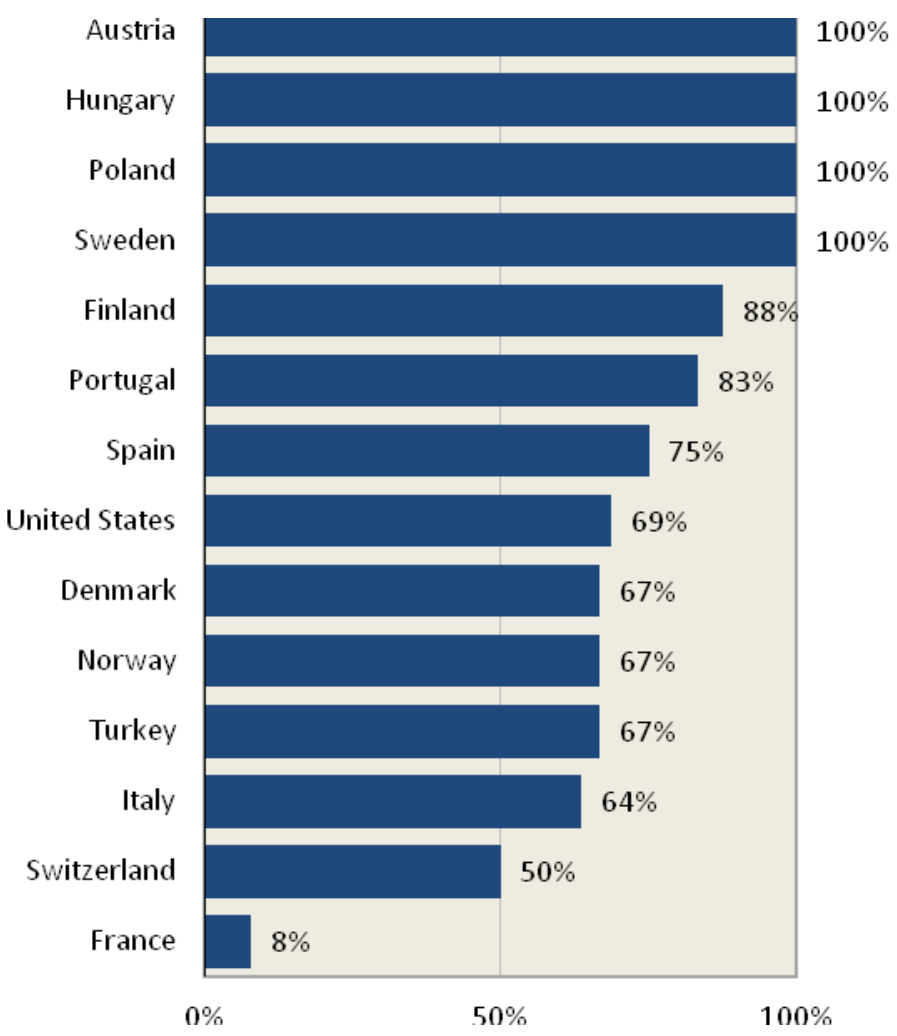

Source: OECD Regions at a Glance

Remote rural regions in Canada and Mexico are significantly worse off in employment opportunities (Figure 5). It must be noted, however, that in Canada this group of regions is also characterised by the biggest range between the minimum and maximum rates. Similarly, European remote rural regions are characterized by very different employment rates and on average they perform better than rural regions close to a city (but worse than urban and intermediate regions). Finally, in terms of employment, remote rural regions and rural regions close to a city in the United States do not differ. The first group displays on average a slightly higher employment rate (higher median) and the dynamics of the employment in the last years are quite similar (Figure 5). Moreover, the results of non-parametric tests for the employment rate show that both PRR and PRC regions come from the same distribution. 
Figure 5. Employment rates in North American regions by extended typology
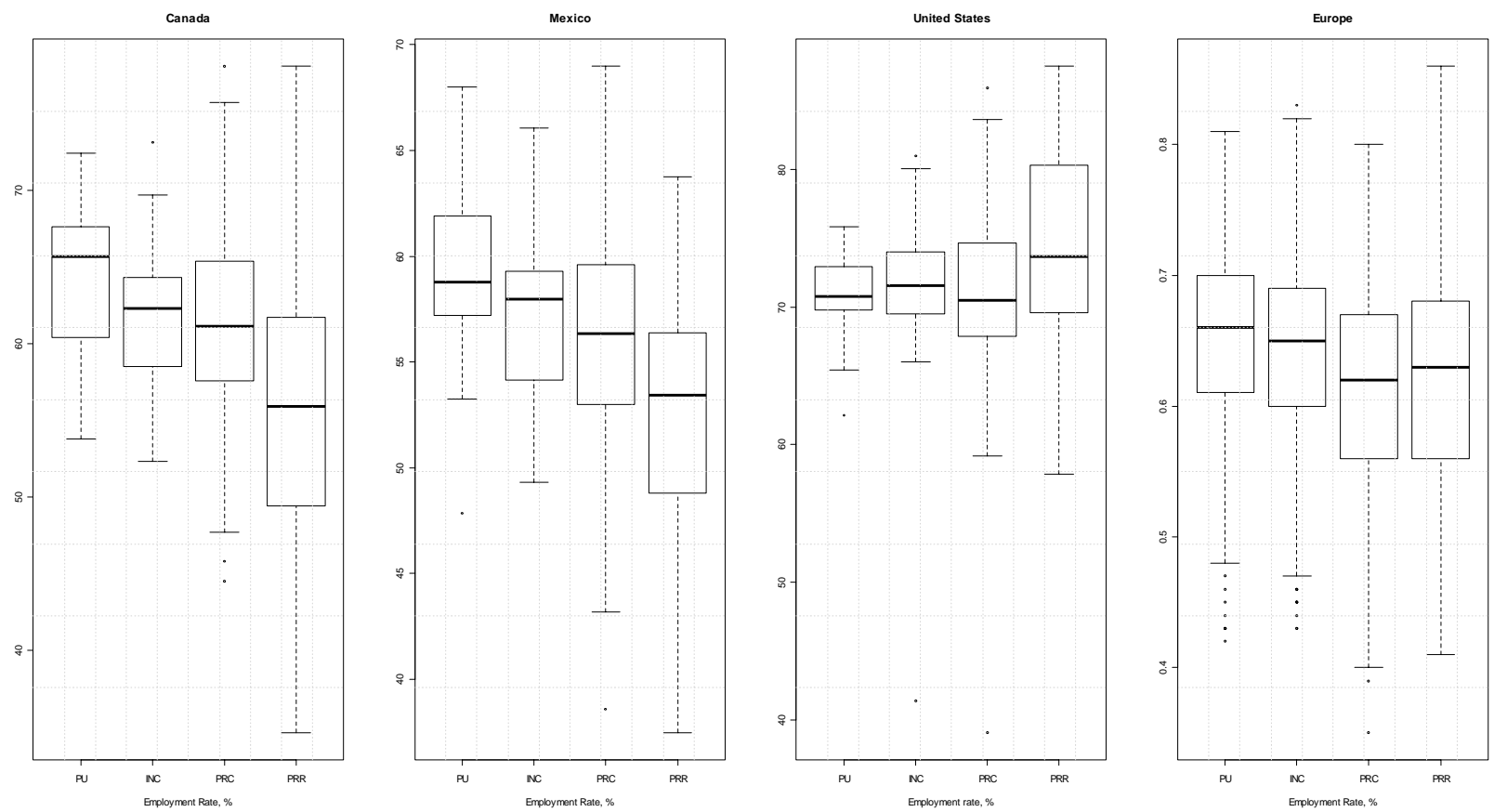

The mix results in terms of population dynamics - characterized by slower growth and net negative outflows of working age population - and employment rates in remote rural areas can be complemented by an analysis of the labour productivity growth in the past 15 years. Growth of labour productivity is a key indicator to assess regional competitiveness as regional differences in GDP per capita are mainly explained by productivity differentials (OECD 2011). Among the 21 OECD countries considered (Europe, Japan and Korea), rural regions increased their labour productivity more than urban regions during 1995-2007. Among rural regions, gains in productivity were greatest in rural regions close to cities $(2 \%)$ while remote rural regions grew at $1.3 \%$ (Figure 6). Data currently available does not permit an analysis of growth patterns under the new typology for North America where GDP figures are not available for small regions (so called TL3 regions). 
Figure 6. Labour productivity growth by regional type, 1995-2007

in urban intermediate $\bigcirc$ in rural close $\bigcirc$ in rural remote

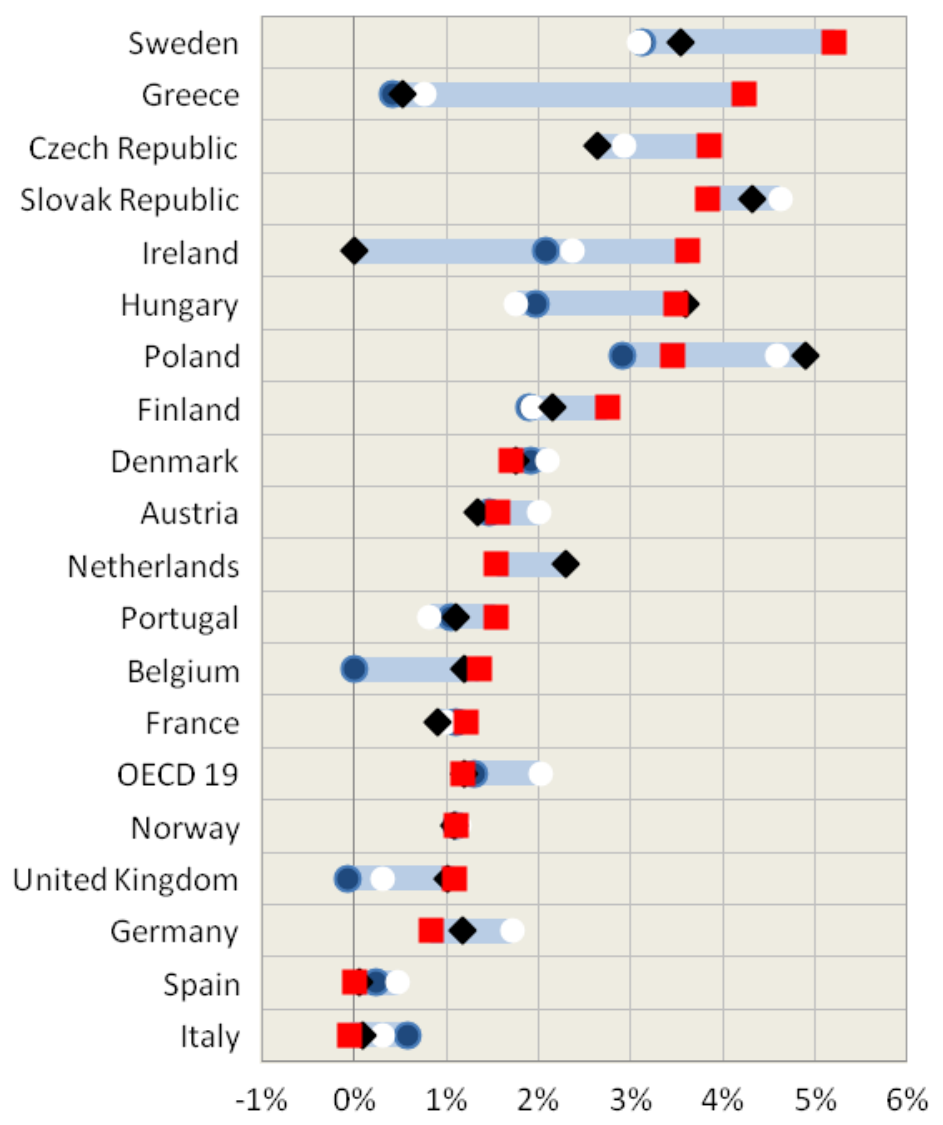

Source: OECD Regions at a Glance

The previous results on Canada, Mexico, the United States and Europe show that there is a high degree of heterogeneity within the group of regions currently classified as rural. This extended typology, adopted by the OECD in 2009, can provide a better snapshot of rural regions. Hence, a more robust classification that maximises the heterogeneity between groups of regions and minimises it inside of them could provide a better understanding of the regional performance and thus help providing better evidence for policy-making.

The extended typology, which classifies regions as PU, IN, PR close to a city and PR remote, should be applied to the remaining OECD countries, whether data inputs (in particular country road network, a map containing the distribution of population and a map containing populated centres with at least 50000 inhabitants) would be made available. The way forward includes the evaluation of how this extended typology can be applied also to non OECD countries and whether some parameters should be changed to better identify specific characteristics of rurality in non OECD countries. 


\section{Annex Methodology}

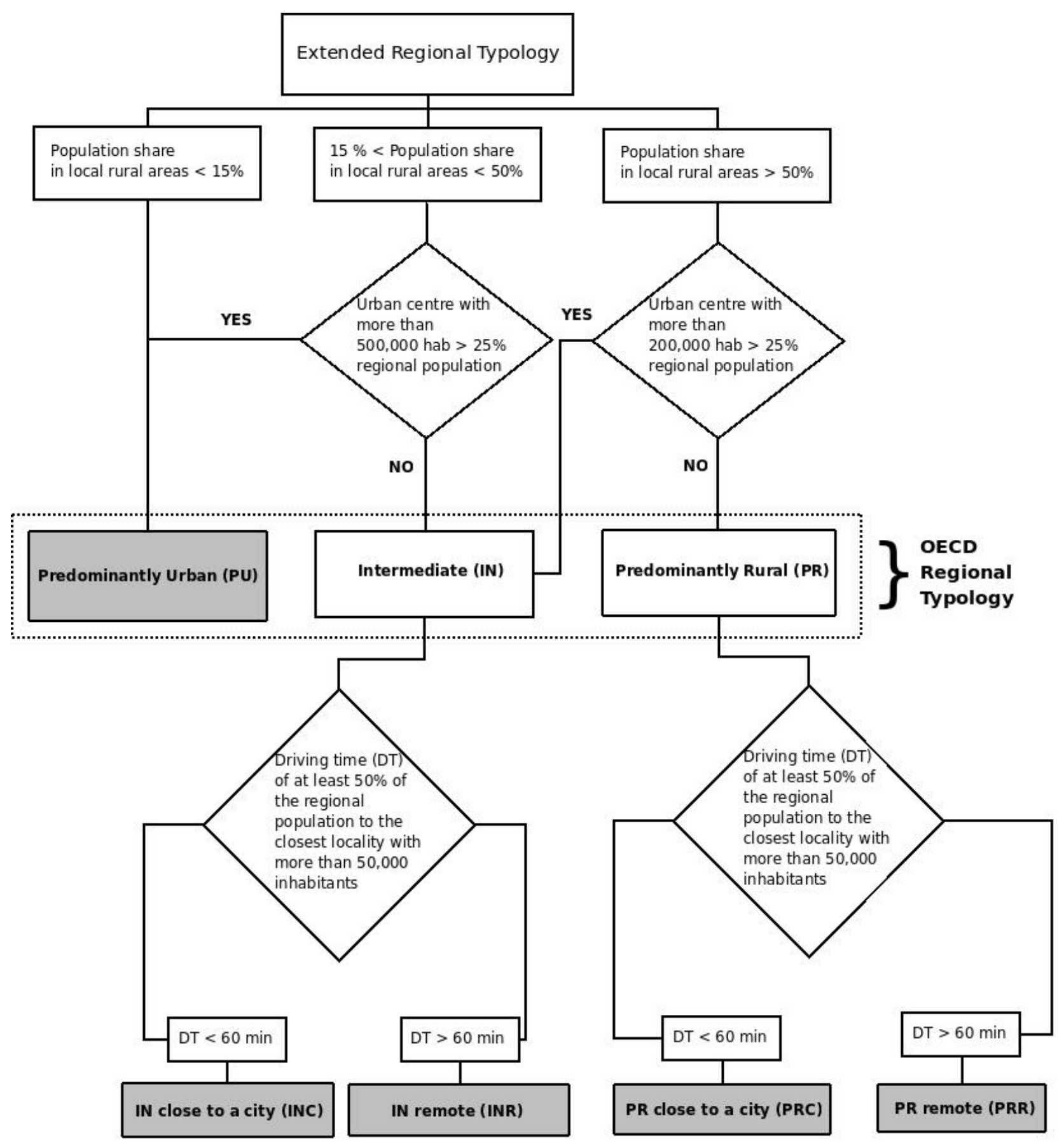

The accessibility analysis used to build the typology for North America was carried by the OECD following the methodology proposed by the Directorate General for Regional Policy of the European Commission. The details of this analysis are explained in the following paragraphs. For further information on the methodology used to build the typology for Europe, please refer to Dijkstra and Poelman (2008).

In a first step, based on the share of population living in local rural areas within each region regions are classified as Predominantly Urban (PU), Intermediate (IN) or Predominantly Rural (PR). An additional criterion is based on the size of the urban centres contained in the TL3 regions. A region previously 
classified as PR (IN), becomes IN (PU) if it contains an urban centre with at least 200000 (500 000) inhabitants representing $25 \%$ of the regional population. These three categories are known as the OECD regional typology. In a second step, the OECD regional typology is extended by considering the driving time of at least $50 \%$ of the regional population to the closest populated centre with more than 50000 inhabitants. This only applies to the IN and PR categories, since by definition the PU regions include highly populated localities. The result is a typology containing five categories: PU, INC, INR, PRC, and PRR.

\section{Accessibility Analysis}

In order to identify a region as remote it is needed to perform an accessibility analysis. This type of analysis quantifies the driving time needed for a certain percentage of the population of a region to reach a populated centre. A region is considered to be remote if at least $50 \%$ of its population needs to drive 60 minutes or more to reach a populated centre with more than 50000 inhabitants. Due to the lack of data, Hawaii, Alaska and Puerto Rico have been excluded from the accessibility analysis applied to the United States. The main inputs of the accessibility analysis are:

- A map containing the distribution of the population

- A road network

- A map containing populated centres with at least 50000 inhabitants

- The analysis can be further refined by considering some additional factors that affect the driving time. This implies the use of a Digital Elevation Model (DEM) and an Urban Areas map.

\section{Distribution of the population}

In order to count the number of people living within each TL3 region, it is necessary to know how the population is distributed along the territory. This information is usually represented by a population density map in a raster format. Since this type of map was not available for Mexico, it has been created using data at the locality level from the 2005 census (INEGI). Rural localities were only available as a point feature class, while urban localities were available as both point and polygon feature class. Hence, the population density map was built using the rural localities as point feature class and the urban localities as polygon feature class. To do so, it has been assumed that the rural localities were concentrated and uniformly distributed around their coordinates. In the case of the United States, the population density map was created using tract data from the 2000 Census, while for Canada this map was created using block data from the 2006 census. Population density was then calculated by dividing the population in each tract and block by its corresponding area.

For the three countries, the population density maps were rasterised. To do so, a first raster map of the population density was created using a $100 \mathrm{~m}$ grid. From this map, a second map was created using a $1 \mathrm{~km}$ grid. This technique reduces the bias caused by the interpolation carried out while assigning a value to the grid's cells. As a result, a map of the population density in raster format was obtained, where every cell corresponds to the population by square kilometre. It is important to bear in mind that this is an approximation of the real distribution of the population, which is based on the assumptions previously mentioned. 


\section{Road Network}

The road network is used to compute the driving time needed to reach urban centres. In the case of Mexico, the road network provided by INEGI includes many types of roads classified according to their number of lanes and structures. To simplify the composition of the network, and to deal with the absence of some interconnections, three main types of roads were chosen: Paved Roads, Non-Paved Roads and Paths. Despite this dataset being quite complete, there were certain issues that had to be overcome before using it in the accessibility analysis. In the first place, not all the roads were connected to the network. Moreover, some pieces of the network were completely isolated. In the second place, since the localities are represented as a point feature class, they were not connected to the network. To tackle these problems, the network was cleaned up by removing the isolated segments and a new set of segments to join the network to the localities was created. In the case of the United States, the road network used for the analysis comes from the National Transportation Atlas Database. For practical reasons, only national highways were considered for the analysis. The national highways dataset is composed by 174540 observations, including interstate, freeways, expressways, and other minor arterials. In the case of Canada, the road network was obtained from Statistics Canada and it was classified in three types of segments: highways, roads, and connecting streets.

\section{Populated Centres}

For Mexico, populated centres were obtained from the urban localities dataset provided by the INEGI while for the United States and Canada, these data came from the 2000 Census Gazetteer files and the North American Atlas, respectively. Once these datasets were filtered, there were 195 populated centres with at least 50000 inhabitants in Mexico, 662 in the United States and 52 in Canada.

\section{Additional factors}

The driving time to reach a populated centre can be influenced by several factors, in particular, the driving speeds, the traffic around urban areas and the slope of the roads. To take into account these three factors, a slope and a density index were computed for the three countries.

The slope index is a proxy for the influence of the terrain. The slope of terrain was calculated using a digital elevation terrain model. The resulting slope values were reclassified in three intervals: 0\%-5\%, $6 \%-11 \%$, and more than $11 \%$. For the first interval, the slope index takes a value equal to 1 , while for the second and third intervals it takes the values of 1.2 and 1.5 , respectively.

The density index is a proxy for the congestion around urban areas. This variable assigns a value to each road segment depending on the type of road it belongs to, and whether the segment is inside of an urban polygon. In the case of Mexico, for every segment outside an urban polygon the density index takes a value equal to 1; for segments within an urban polygon, the density index takes a value of 1.5 if the segment belongs to a paved road, 1.8 if the segment belongs to a non-paved road, and 2 if the road belongs to a path or if it belongs to one of the segments created to join the localities to the network. In the case of the United States, two main types of roads have been identified from the national highways dataset: Principal arterials and Minor arterials. Principal arterials include interstate highways, freeways and expressways, while minor arterials include minor and major collectors as well as local roads. To simplify the analysis, it was assumed that no traffic is found outside urban areas, while the traffic in urban areas has a bigger effect on minor arterials than on the principal ones. A weight equal to 1 was given to all road segments outside an urban area, while Principal and Minor arterials within an urban area respectively received weights equal to 1.5 and 2. The same type of weighting was used for Canada, where the highways received a value equal to 1.5 , while the roads and connecting streets received a value equal to 2 . 
Since the speed limits in Mexico often change within the same type of road, choosing a value for every type of road was not an easy task. Following the recommendations provided by the Ministry of Communications and Transport to foreigners driving in Mexico, the following values for each type of road were selected: $100 \mathrm{~km} / \mathrm{h}$ for the paved roads, $50 \mathrm{~km} / \mathrm{h}$ for the non-paved roads and the segments joining localities to the network, and $30 \mathrm{~km} / \mathrm{h}$ for the paths. In the US, speed limits are defined by each State, mainly depending on the land use. However, speed limits may change depending on the time of day and the type of vehicle. For practical reasons, only day time limits for non-truck vehicles have been used, taking into account whether a highway segment belongs to an urban or a rural area. In the case of Canada, the speed limits are defined according to type and location of the road. Indeed, segments of highways located in rural areas have a maximum speed limit of $100 \mathrm{~km} / \mathrm{h}$, while the rest of highway segments are limited to $80 \mathrm{~km} / \mathrm{h}$. Connecting streets have a limit of $50 \mathrm{~km} / \mathrm{h}$.

Finally, the road network was intersected with the slope and urban polygons layers to create a road network where every segment has a specific value assigned for the slope of the terrain and a value to indicate if the segment belongs to an urban polygon. From this layer, the crossing time of every segment in the network can be calculated as follows:

$$
C T_{i}=\frac{\text { (Distance of the segment } * \text { slope index } * \text { density index) }}{\left(\text { Speed limit } * \frac{1000}{60}\right)}
$$

\section{Service Areas}

To carry on with the accessibility analysis, once the density population map and the road network were ready, it was necessary to define the service areas surrounding every populated centre with at least 50000 inhabitants. A service area is a region that encompasses all accessible roads. The size of a service area depends on the time needed to access a certain point, in this case a populated centre. For instance, a 60-minute service area for a specific locality includes all the roads in the network that can be reached from that locality within 60 minutes. In Figure 6 , the service areas, the localities with more than 50000 inhabitants and the road network are shown for the east-coast of the U.S. The service areas are represented by the concentric rings around the localities. These service areas were calculated for different time frames: 30 minutes (yellow), 60 minutes (orange) and 90 minutes (red). In this map, the service areas are represented by blue concentric polygons surrounding the cities (red points). Light blue polygons represent a 30 minutes service area, while medium blue and dark blue represent respectively 60 and 90 minutes service areas. 
Figure 7. Elements for the accessibility analysis

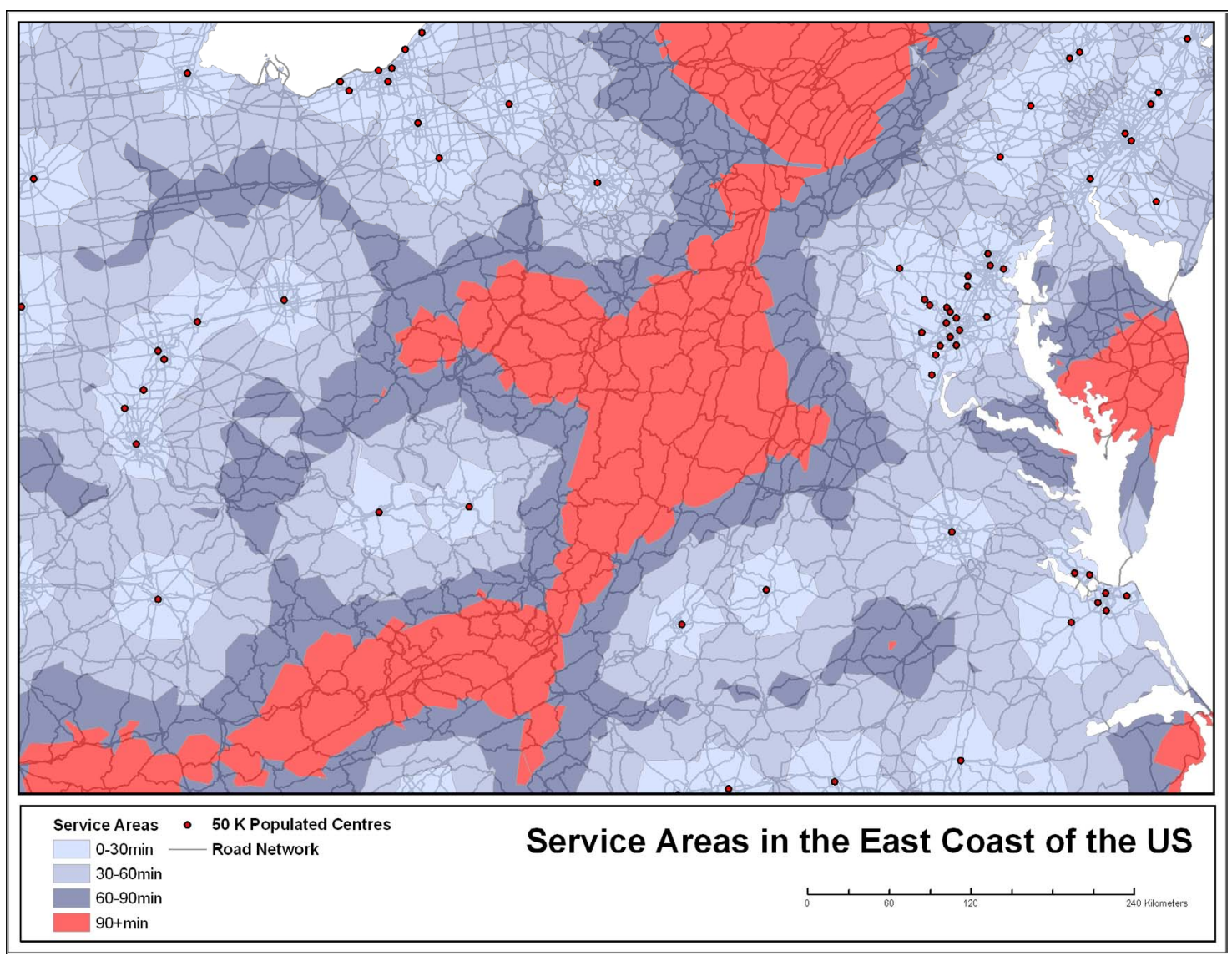

Using the service areas a region can be classified as remote (or close to a city) by calculating the percentage of people living within a specific time frame. For the current analysis it has been considered a 60 -minute time frame, and a percentage of population of 50\%. Hence, if less than $50 \%$ of the population lives within the 60-minute service area, the region was considered to be remote.

The results obtained from this analysis depend on the parameters used to model the accessibility to the localities, i.e. the crossing time, the size of the localities and the time frame. Initially, two sizes for the localities had been considered: 50000 and 100000 inhabitants. However, based on the definition of a locality, 50000 was considered to be a more adequate size. Since cities are composed by localities, using a bigger size may exclude localities within big cities or metropolitan areas.

Regarding the time frame used for the analysis, the three thresholds shown in Figure 6 were considered. Since a 30-min drive is common in big countries like Mexico, the United States and Canada, it was decided to focus on the other two time frames. It can be seen that the classification of regions is significantly affected by the choice of the time frame. Table 2 shows that for a 60 -minutes time frame in Mexico, 63 regions are classified as remote, while for a 90-min time frame only 38 regions fall in the category. The decrease in the number of regions is proportional to the decrease in the population for each class. Using a time frame of 90 minutes reduces the percentage of people living in remote areas by almost a half. Nevertheless, the distributions of the employment and population growth rate variables, for the 60min and 90-min time frames seem to be quite similar. Similarly, in the case of the United States, when using a 90 minutes the percentage of inhabitants in remote areas is reduced by half, while the number of regions classified as "Remote" is also significantly reduced, going from 32 to 19 regions. This is also the case for Canada. For this reason, it was decided to only consider the results of a 60-min time frame. 
Table 2. Number of regions and percentage of population by typology based on 90 minutes of driving time, Mexico

\begin{tabular}{|c|c|c|c|c|c|c|c|}
\hline & \multirow[b]{2}{*}{ OECD Typology } & \multicolumn{2}{|c|}{ Close to a City } & \multicolumn{2}{|c|}{ Remote } & \multicolumn{2}{|c|}{ Totals } \\
\hline & & N. of regions & Population & N. of regions & Population & N. of regions & Population \\
\hline & IN & 33 & $98 \%$ & 2 & $2 \%$ & 35 & $100 \%$ \\
\hline \multirow[t]{4}{*}{ Canada } & PR & 99 & $61 \%$ & 124 & $39 \%$ & 223 & $100 \%$ \\
\hline & PU & 30 & $100 \%$ & - & $0 \%$ & 30 & $100 \%$ \\
\hline & Total & 162 & $88 \%$ & 126 & $12 \%$ & 288 & $100 \%$ \\
\hline & IN & 29 & $98 \%$ & 1 & $2 \%$ & 30 & $100 \%$ \\
\hline \multirow[t]{4}{*}{ Mexico } & PR & 107 & $85 \%$ & 38 & $15 \%$ & 145 & $100 \%$ \\
\hline & PU & 34 & $100 \%$ & - & $0 \%$ & 34 & $100 \%$ \\
\hline & Total & 170 & $94 \%$ & 39 & $6 \%$ & 209 & $100 \%$ \\
\hline & IN & 21 & $100 \%$ & 0 & $0 \%$ & 21 & $100 \%$ \\
\hline \multirow[t]{3}{*}{ U.S. } & PR & 112 & $95 \%$ & 19 & $5 \%$ & 131 & $100 \%$ \\
\hline & PU & 25 & $100 \%$ & 0 & $0 \%$ & 25 & $100 \%$ \\
\hline & Total & 158 & $98 \%$ & 19 & $2 \%$ & 177 & $100 \%$ \\
\hline
\end{tabular}


Figure 8. Service areas for 30-min, 60-min and 90-min time frames, North America

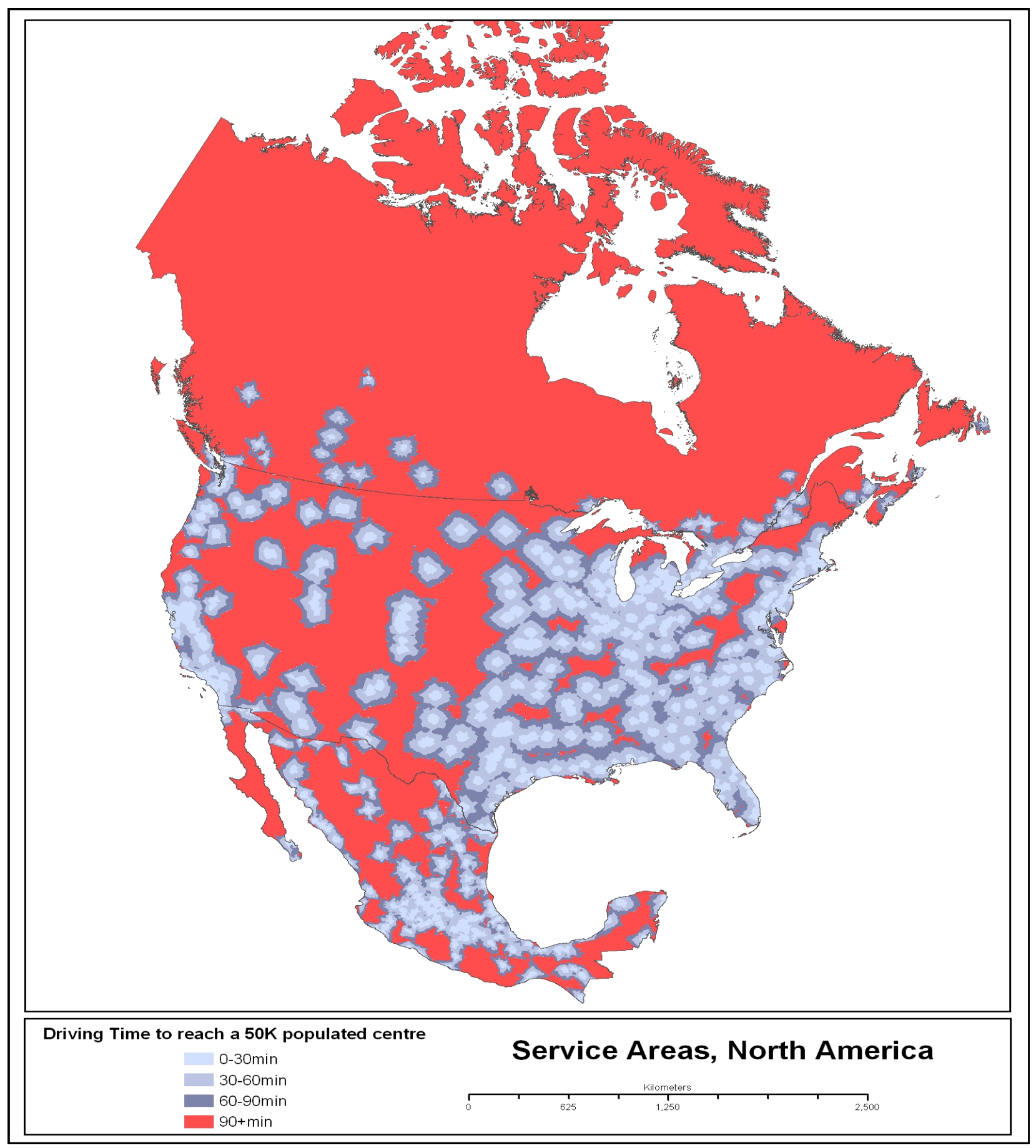




\section{BIBLIOGRAPHY}

Bollman, R. (2008) "Factors driving Canada's rural economy" Statistics Canada, Agriculture and Rural Working Paper No. 83.

Dijkstra, L. and H. Poelman (2008) "Remote Rural Regions: How the proximity to a city influences the performances of rural regions" Regional Focus No 1.

http://ec.europa.eu/regional_policy/sources/docgener/focus/2009_01_metropolitan.pdf.

OECD (2011), OECD Regions at a Glance, OECD Publishing, Paris.

OECD (2010) Labour mobility and development dynamics in OECD regions [GOV/TDPC/TI(2010)1].

OECD (2009) "Regional typology: Updated statistics", www.oecd.org/gov/regional/statisticsindicators. 